\title{
Effects of Vegetation Restoration on Soil Organic Carbon in China: A Meta-analysis
}

\author{
GONG Li $^{1,2}$, LIU Guohua ${ }^{1,2}$, WANG Meng ${ }^{1,2}$, YE Xin ${ }^{1,2}$, WANG Hao ${ }^{1,2}$, LI Zongshan ${ }^{1}$ \\ (1. State Key Laboratory of Urban and Regional Ecology, Research Center for Eco-environmental Sciences, Chinese Academy of Sci- \\ ences, Beijing 100085, China; 2. University of Chinese Academy of Sciences, Beijing 100049, China)
}

\begin{abstract}
Vegetation restoration has been proposed as an effective method for increasing both plant biomass and soil carbon (C) stocks. In this study, 204 publications (733 observations) were analyzed, focusing on the effects of vegetation restoration on soil organic carbon (SOC) in China. The results showed that SOC was increased by $45.33 \%, 24.43 \%, 30.29 \%$ and $27.98 \%$ at soil depths of $0-20 \mathrm{~cm}, 20-40$ $\mathrm{cm}, 40-60 \mathrm{~cm}$ and $>60 \mathrm{~cm}$ after vegetation restoration, respectively. Restoration from both cropland and non-cropland increased the SOC content. The conversion of non-cropland was more efficient in SOC accumulation than the conversion of cropland did, especially in $>40 \mathrm{~cm}$ layers. In addition, the conversion to planted forest led to greater SOC accumulation than that to other land use did. Conversion period and initial SOC content extended more influence on soil $\mathrm{C}$ accumulation as the main factors after vegetation restoration than temperature and precipitation did. The SOC content significantly increased with restoration period after long-term vegetation restoration ( $>40 \mathrm{yr}$ ), indicating a large potential for further accumulation of carbon in the soil, which could mitigate climate change in the near future.
\end{abstract}

Keywords: soil carbon content; vegetation restoration; land-use change; conversion period; restoration approach; China

Citation: Gong Li, Liu Guohua, Wang Meng, Ye Xin, Wang Hao, Li Zongshan, 2017. Effects of vegetation restoration on soil organic carbon in China: a Meta-analysis. Chinese Geographical Science, 27(2): 188-200. doi: 10.1007/s11769-017-0858-x

\section{Introduction}

Soil carbon accounts for $75 \%$ of total terrestrial carbon, and plays a significant role in the variation of atmospheric carbon dioxide $\left(\mathrm{CO}_{2}\right)$ concentrations (Henderson, 1995; Song et al., 2014). In the past two centuries, conversion of natural vegetation to cropland is believed to increase the atmospheric $\mathrm{CO}_{2}$ concentrations (Houghton et al., 1999; Paul, 2002; Foley, 2005; Nouvellon et al., 2012). Conversion of forest and pasture to cropland caused carbon loss from soil. Soil carbon stocks decreased by $42 \%$ and $59 \%$ after the conversion of forest and pasture to cropland, respectively (Guo and Gifford, 2002). Soil organic carbon (SOC) decreased by $25.2 \%$, $21.3 \%$ and $10.4 \%$ by conversion of primary forest, sec- ondary forest and grassland to cropland in the tropics, respectively (Don et al., 2011). In contrast, SOC accumulated after conversion of cropland to perennial vegetation via increasing carbon derived from the new vegetation, thus alleviating the carbon loss from decomposition and erosion (Richter et al., 1999; Lal et al., 2002; Lal, 2004; Laganière et al., 2010; Chang et al., 2011). Soil carbon increased by 53\%, $19 \%$ and $18 \%$ after conversion of cropland to secondary forest, tree plantation and pasture, respectively (Guo and Gifford, 2002). SOC increased by $25.7 \%$ and $17.5 \%$ after conversion of cropland to grassland and conversion of grassland to secondary forest in tropical areas, respectively (Don et al., 2011). Therefore, vegetation restoration has been one of the significant strategies for climate change

Received date: 2016-07-12; accepted date: 2016-11-17

Foundation item: Under the auspices of Strategic Priority Research Program of Chinese Academy of Sciences (No. XDA05060104)

Corresponding author: LIU Guohua. E-mail: ghliu@rcees.ac.cn

(C) Science Press, Northeast Institute of Geography and Agroecology, CAS and Springer-Verlag Berlin Heidelberg 2017 
mitigation (Zhang et al., 2010). However, some studies reported that reforestation and afforestation of farmlands did not increase soil carbon (Bashkin and Binkley, 1998; Vesterdal et al., 2002), or decreased SOC stocks during the initial 4-5 yr (Zhang et al., 2010; Deng et al., 2014).

SOC accumulation following land use change is affected by multiple factors including climate condition, land use history, vegetation type and site management, etc. (Guo and Gifford, 2002; Paul et al., 2002; Lal, 2004; Laganière et al., 2010; Li et al., 2012). In addition, SOC accumulation can be affected by variant factors under different scale. Paul et al. (2002) concluded that climate ranked a significant factor influencing change in soil carbon $(<30 \mathrm{~cm})$ after afforestation based on global data. However, land-use change such as the Grain for Green Program (GGP) largely increased the SOC in central and western China (Deng et al., 2014; Song et al., 2014). Therefore, knowing the factors affecting SOC accumulation under different land-scale and utilizing appropriate ecosystems management would benefit for soil carbon sequestration via afforestation (Post and Kwon, 2000; Lal, 2004; Li et al., 2012).

In China, soil degradation and desertification has been caused by long-term agricultural exploitation (Lal, 2002). In order to restore the degraded environment, GGP project, the nation's largest ecological restoration project since the $1970 \mathrm{~s}$, was launched by the Chinese government. By 2012, $9.06 \times 10^{6}$ and $6.40 \times 10^{5}$ ha cropland had been converted to forest and grassland, respectively (State Forestry Administration, 2013). The large scale change in land use undertaken in China may indeed affect carbon sequestration capacity in terrestrial ecosystem. However, studies on the changes in soil carbon were based on forest-stand and/or regional scale, which brought about conflicting results due to variant restoration period and climate conditions ( $\mathrm{Li}$ et al., 2005; Xiao et al., 2013), limiting the evaluation on the capacity of soil carbon accumulation during restoration. In addition, studies on the effects of the conversion of cropland have been reported (Song et al., 2014). However, few studies were reported on the conversion of non-agricultural land to natural forest and/or grassland (Zhou et al., 2006).

Meta-analysis, a powerful statistical technique for comparing and integrating the results from multiple independent studies, has been successfully used to evalu- ate the effects of land-use change (Guo and Gifford, 2002), enhancement of biodiversity and ecosystem Services (Benayas et al., 2009), tillage management (Van et al., 2013), forest management (Johnson and Curtis, 2001), and grassland management (Conant et al., 2001). In this study, a meta-analysis was conducted by analyzing previous studies conducted in China, as to investigate whether the directions and magnitudes of the vegetation restoration effects on SOC content differ based on the following variables: 1) ex-land use (non-cropland or cropland), 2) plantation type (conversion of cropland to forest, shrub land, grassland; conversion of pasture to grassland, conversion of plantation to natural forest and conversion of wasteland to plantation), 3) conversion period (i.e., time since conversion), and 4) mean annual temperature (MAT) and mean annual precipitation (MAP).

\section{Materials and Methods}

\subsection{Data sources and calculations}

Data and site information, as widely collected from literatures concerning soil carbon change following conversion of crop land, long-time closing hillsides, grassland fencing and establishment, were utilized in meta-analysis. Literature searching was performed via online reference database including Web of Science and The China Knowledge Resource Integrated Database, with 'vegetation restoration' and 'land use change' identified as key words. Data were extracted from publications reporting on the SOC or soil organic matter (SOM) contents in both restoration plots and control plots (i.e., cropland). Factors including climate conditions (precipitation and temperature), longitude, latitude, soil bulk density, soil sampling depth, restoration period and restoration modes were also extracted.

In some studies, only SOM was reported, soil organic carbon concentration $\left(S O C_{c}\right)(\mathrm{g} / \mathrm{kg})$ values are calculated as following (Guo and Gifford, 2002):

$$
S O C_{c}=S O M \times 0.58
$$

where $S O C_{c}$ is soil organic carbon concentration $(\mathrm{g} / \mathrm{kg})$; $S O M$ represents soil organic matter $(\mathrm{g} / \mathrm{kg})$,

In other studies, only soil organic carbon stocks $\left(S O C_{s}\right)$ was reported, $S O C_{c}(\mathrm{~g} / \mathrm{kg})$ values are calculated as following (Guo and Gifford, 2002):

$$
S O C_{c}=\frac{10 \times S O C_{s}}{D \times B D}
$$


where $S O C_{s}$ is soil organic carbon stocks $(\mathrm{Mg} / \mathrm{ha}) ; B D$ is soil bulk density $(\mathrm{g} / \mathrm{cm})$ and $D$ is soil thickness $(\mathrm{cm})$.

A total of 137 publications containing 777 observations in 29 provinces, municipalities and autonomous region (from 1998 to 2016) (Fig. 1) were selected to conduct a comprehensive analysis. The selected observations were divided into four categories (based on the SOC sampling depth) as follows: $0-20 \mathrm{~cm}, 20-40 \mathrm{~cm}$, $40-60 \mathrm{~cm}$ and $>60 \mathrm{~cm}$. In addition, the observations were subdivided for each soil layer based on the initial SOC content in land use types (cropland or non-cropland), plantation types (forest, shrub land, grassland), as to better understand the factors regulating the direction and magnitude of SOC following restoration. Mean annual temperature (MAT) and mean annual precipitation (MAP) were also collected.

\subsection{Meta-analysis}

The effect size for each investigation (i.e., the response ratio) was calculated as follows (Cooper and Hedges, 1994):

$$
r=\chi_{e} / \chi_{c}
$$

where $r$ represents the response ratio, $\chi_{e}$ is the mean $\mathrm{SOC}_{\mathrm{c}}$ in restoration plots, $\chi_{c}$ is the mean SOC in the associated control plots.

To be used statistically, $r$ must be log transformed as follows:

$\ln (r)=\ln \left(\chi_{e}\right)-\ln \left(\chi_{c}\right)$

In order to maximize the number of observations in the selected studies, an unweighted meta-analysis was used as described previously (Guo and Gifford, 2002).

Mean effect size for each categorical subdivision was calculated via Meta-Win 2.0 software, with a bias-corrected 95\% confidence intervals (CIs) generated by a bootstrapping procedure (Song et al., 2014). The effect of vegetation restoration on the SOC within a categorical subdivision was considered significant at $P<0.05$ if the $95 \%$ CIs did not include 0 (Guo and Gifford, 2002). The total heterogeneity among groups $\left(Q_{t}\right)$ was partitioned into within-group heterogeneity $\left(Q_{w}\right)$ and be tween-

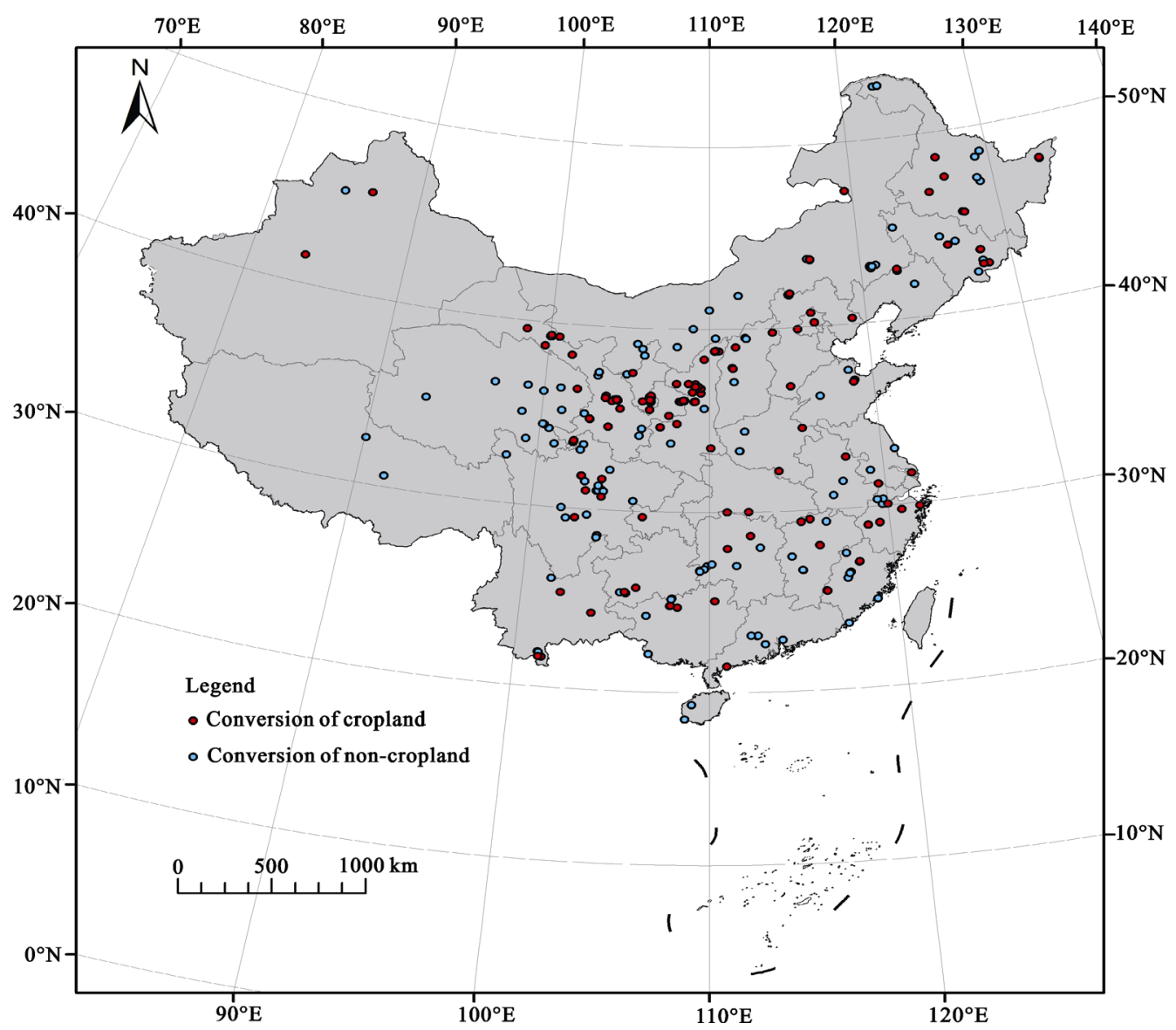

Fig. 1 Site distribution of studies on vegetation restoration included in the meta-analysis 
group heterogeneity $\left(Q_{b}\right)$ (i.e., $\left.Q_{t}=Q_{w}+Q_{b}\right)$. The $Q_{b}$ for each categorical variable was determined for the response variable. A significance of $Q_{b}$ indicated that effect size was different between different categorical subdivisions.

\section{Results}

Studies on the effects of vegetation restoration on SOC included 733 observations from 204 papers, in which 333 observations were related to restoration from cropland and 400 observations were related to restoration from non-cropland. The database covers provinces, municipalities and autonomous region in China, but most studies under restoration from cropland were in the following Loess Plateau, Middle-lower Yangtze Area and the Region of Hengduan Mountains.

\subsection{Effects of vegetation restoration on SOC}

Fig. 2 shows the SOC contents changes at different soil depths in response to vegetation restoration. The SOC content increased by $45.3 \%, 24.4 \%, 30.3 \%$ and $28.0 \%$ after vegetation restoration at the soil depth of $0-20 \mathrm{~cm}$, 20-40, 40-60 cm and $>60 \mathrm{~cm}$, respectively. In response to the restoration from cropland, SOC contents increased by $41.7 \%$ at soil depth of $0-20 \mathrm{~cm}$, which was greater than the incensement at soil depths of $20-40 \mathrm{~cm}$ (19.3\%), 40-60 cm (11.0\%) and $>60 \mathrm{~cm}(18.6 \%)$. Similarly, In response to the restoration from cropland, the SOC contents increased by $48.4 \%$ and $51.2 \%$ at soil

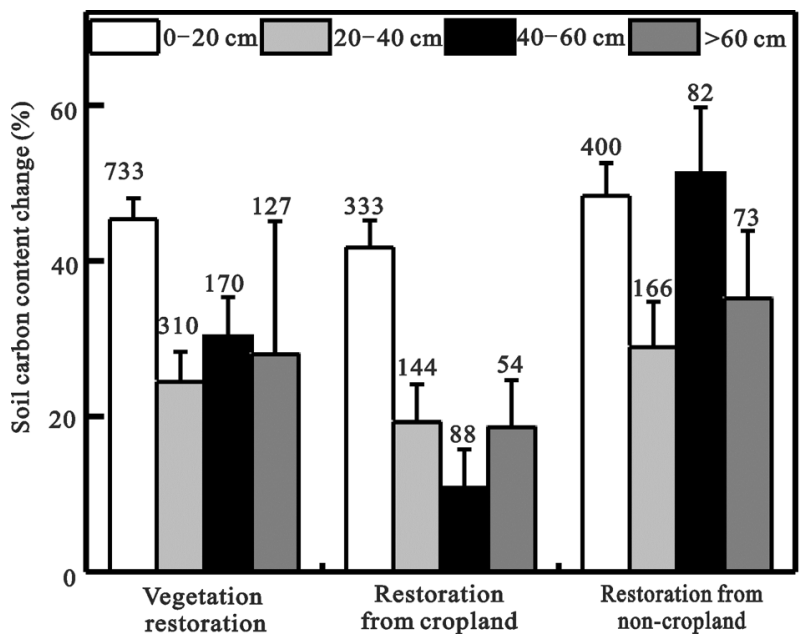

Fig. 2 Response ratios pertaining to effects of vegetation restoration on soil organic carbon contents at different soil depths. The error bars represent $95 \%$ confidence intervals (CI) and values above the bars are the corresponding number of observations depths of $0-20 \mathrm{~cm}$ and $40-60 \mathrm{~cm}$, which are greater than the increase at soil depth of $20-40 \mathrm{~cm} \mathrm{(29 \% )} \mathrm{and} \mathrm{>}$ $60 \mathrm{~cm}(35.1 \%)$. The results indicated that the increase in SOC content at soil depth of $0-20 \mathrm{~cm}$ under restoration from cropland showed no significant difference from the restoration from non-cropland. In contrast, the increase in SOC content at soil depth of $20-40 \mathrm{~cm}, 40-60 \mathrm{~cm}$ and $>60 \mathrm{~cm}$ under restoration from non-cropland were significantly higher than that under the restoration from cropland $(P>0.05)$.

\subsection{Effects of vegetation restoration approach on SOC}

Fig. 3 shows the changes of SOC contents following restoration from cropland (Fig. 3a) and non-cropland (Fig. 3b) via variant restoration types. SOC contents increased by $17.7 \%, 2.1 \%$ and $25.5 \%$ at soil depths of $0-20 \mathrm{~cm}, 20-40 \mathrm{~cm}$ and $>60 \mathrm{~cm}$, while decreased by $10.3 \%$ at soil depth of $40-60 \mathrm{~cm}$ under the conversion of cropland to grassland (Fig. 3a). However, SOC contents increased by $59.8 \%, 33.8 \%, 17.4 \%$ and $41.6 \%$ at soil depths of 0-20 cm, 20-40 cm, 40-60 cm and $>60 \mathrm{~cm}$, respectively, following the conversion of cropland to shrub land. Besides, increase of SOC contents by $55.8 \%, 25.3 \%, 20.8 \%$ and $6.5 \%$ at soil depths of $0-20$ $\mathrm{cm}, 20-40 \mathrm{~cm}, 40-60 \mathrm{~cm}$ and $>60 \mathrm{~cm}$ were caused by the conversion of cropland to forests. The results suggested that the response ratios of the SOC content were increased under the restoration from cropland to natural vegetation, and conversion of cropland to shrub land or forest were higher than grassland in the $0-20 \mathrm{~cm}$ and $20-40 \mathrm{~cm}$ soil layers. Following the conversion of pasture to grassland, the SOC contents increased by $54.0 \%$, $29.4 \%$ and $51.9 \%$ at soil depth of $0-20 \mathrm{~cm}, 20-40 \mathrm{~cm}$ and $>60 \mathrm{~cm}$, while decreased by $26.03 \%$ at soil depth of 40-60 cm (Fig. 3b). Under the conversion of grassland to forest, SOC content increased by $65.2 \%, 45.2 \%$ and $58.5 \%$ at soil depths of $0-20 \mathrm{~cm}, 20-40 \mathrm{~cm}$ and $40-60$ $\mathrm{cm}$, while decreased by $55 \%$ at soil depth of $>60 \mathrm{~cm}$. These results suggested that the response ratios of the SOC content under the conversion of grassland to forest were lower than the conversion of pasture to grassland at the no obvious land use change in $<40 \mathrm{~cm}$ soil layers. However, the response ratios of the SOC content under conversion of grassland to forest were higher than the conversion of pasture to grassland at the no obvious land use change in $>40 \mathrm{~cm}$ soil layers. With the conversion 

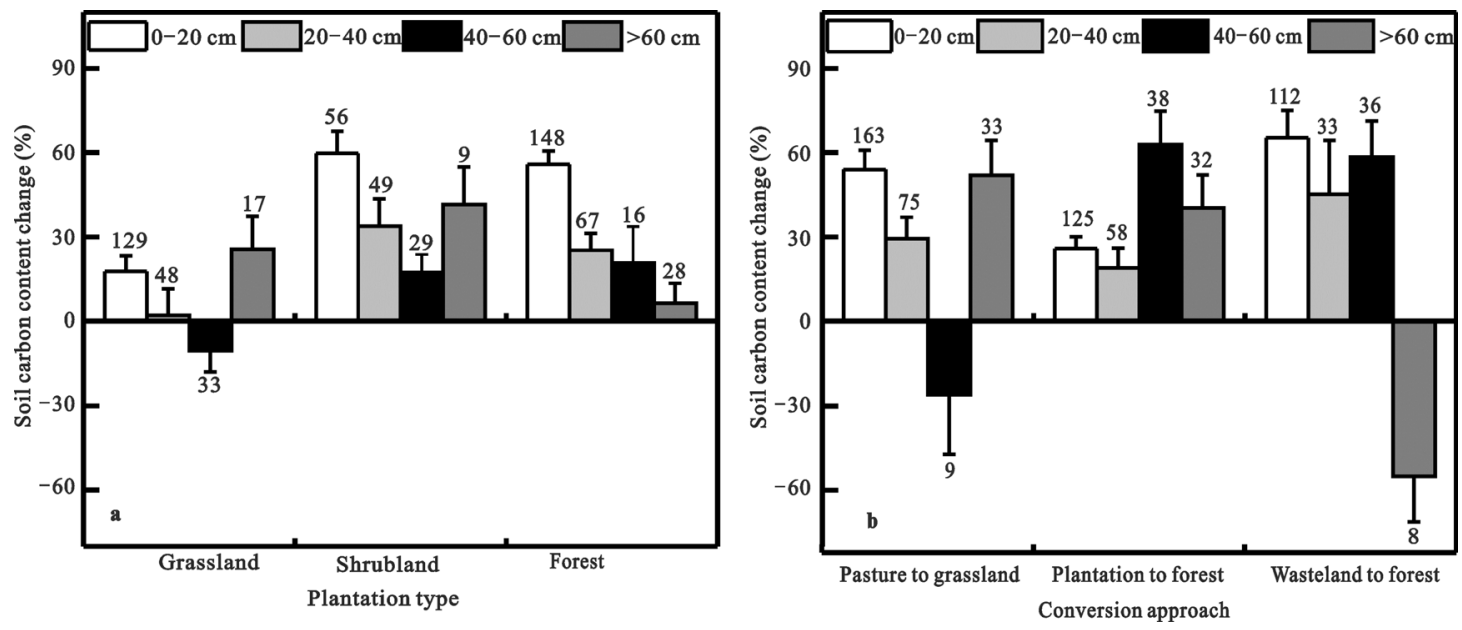

Fig. 3 Response ratios pertaining to the effects of plantation on SOC contents at different soil depths. (a) Restoration from cropland, (b) Restoration from non-cropland. The error bars represent $95 \%$ confidence intervals (CI) and values above the bars are the corresponding number of observations

of wasteland to forest, SOC contents increased by $25.9 \%, 19 \%, 62.9 \%$ and $40.4 \%$ at soil depths of $0-20 \mathrm{~cm}$, $20-40 \mathrm{~cm}, 40-60 \mathrm{~cm}$ and $>60 \mathrm{~cm}$, respectively. These results indicated that the restoration from forest was conducive to the accumulation of the SOC in deeper soil layers.

\subsection{Effects of conversion period on SOC}

Fig. 4 shows the effects of the restoration period on SOC contents at different soil depths after conversion. Generally, SOC content increased with increasing years since vegetation restoration from cropland (Fig. 4a) and non-cropland (Fig. 4b). SOC content in the $0-20 \mathrm{~cm}$ soil slightly decreased by $1.4 \%$ during $1-5 \mathrm{yr}$, then dramatically increased by $30.7 \%$ during $6-10 \mathrm{yr}$, followed by $89.8 \%$ increase after $30 \mathrm{yr}$ restoration from cropland (Fig. 4a). SOC content at $20-40 \mathrm{~cm}$ soil started to decrease by $19.1 \%$ during $1-5 \mathrm{yr}$, then increased by $0.6 \%$ during 6-10 yr, followed by $48.2 \%$ increase after $30 \mathrm{yr}$. SOC content was decreased by $26.4 \%$ at $40-60 \mathrm{~cm}$ soil during $1-5 \mathrm{yr}$ restoration from cropland, then increased by $53.4 \%$ after $30 \mathrm{yr}$. However, SOC content at $>60 \mathrm{~cm}$ soil increased by $31.9 \%$ during $1-5 \mathrm{yr}$, then decreased by $21.3 \%$ after $30 \mathrm{yr}$ restoration from cropland. These results indicated that the response ratios of the SOC content decreased at the early stage of the vegetation restoration from cropland to natural vegetation (1-5 yr), and the loss of SOC could be reduced by reasonable management and restoration types.

SOC content at the $0-20 \mathrm{~cm}$ soil increased by $11.4 \%$ during 1-5 yr restoration from non-cropland, and then gradually increased by $64.4 \%$ during $31-40 \mathrm{yr}$, followed by $106.1 \%$ increase after $40 \mathrm{yr}$ (Fig. $4 \mathrm{~b}$ ). SOC content at $20-40 \mathrm{~cm}$ soil tended to increase by $7.4 \%$ during $1-5 \mathrm{yr}$, then increased by $17.2 \%$ during $21-30 \mathrm{yr}$, followed by dramatic increase of $98.4 \%$ after 40 yr. SOC content decreased by $9.6 \%$ at $40-60 \mathrm{~cm}$ soil during $1-5 \mathrm{yr}$, then increased by $40.5 \%$ during $6-10$ yr restoration from non-cropland, followed by increase of $75.2 \%$ after $40 \mathrm{yr}$. $4.6 \%$ increase of SOC content was observed at $>60 \mathrm{~cm}$ soil during $1-5 \mathrm{yr}$, followed by $50.4 \%$ increase of SOC content during 21-30 yr restoration from non-cropland. Then $33.4 \%$ increase of SOC content was observed at $>60 \mathrm{~cm}$ soil after $40 \mathrm{yr}$. These results indicated that the response ratios of the SOC content did not decrease at the early stage due to the no obvious land use change or conversion of grassland to forest, and suggested that the loss of SOC at early stage in the process of vegetation restoration could be prevented by the protection of natural vegetation and plantation.

\subsection{Effects of mean annual precipitation on SOC}

Fig. 5 depicts the effects of multi-year average precipitation on the SOC content at different soil depths. With restoration from cropland, SOC content at $0-20 \mathrm{~cm}$ soil gradually increased by $17.8 \%, 46.2 \%$ and $50.7 \%$ with the regional precipitation $<400 \mathrm{~mm}, 400-800 \mathrm{~mm}$ and $>800 \mathrm{~mm}$, respectively (Fig. 5a). SOC content at 20-40 $\mathrm{cm}$ was reduced by $0.5 \%$ with precipitation $<400 \mathrm{~mm}$, while tended to increase by $18.7 \%$ and $37.3 \%$ with 

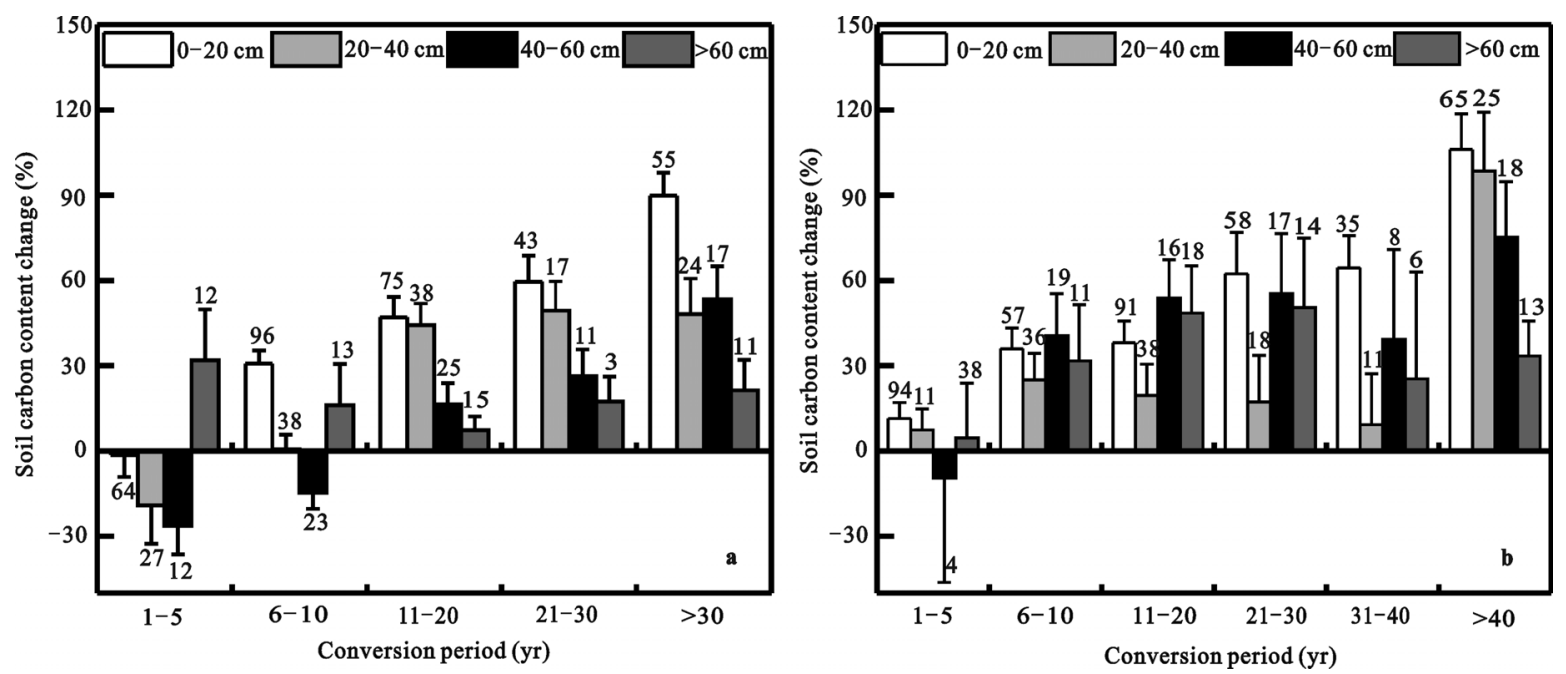

Fig. 4 Response ratios pertaining to the effects of conversion period on SOC contents at different soil depths. (a) Restoration from cropland, (b) Restoration from non-cropland. The error bars represent $95 \%$ confidence intervals (CI) and values above the bars are the corresponding number of observations

precipitation $400-800 \mathrm{~mm}$ and $>800 \mathrm{~mm}$, respectively. At soil depth of 40-60 cm, SOC content was decreased by $23.3 \%$ and $7 \%$ with precipitation $<400 \mathrm{~mm}$ and $>$ $800 \mathrm{~mm}$, while increased by $18.7 \%$ with $400-800 \mathrm{~mm}$ precipitation. SOC content at $>60 \mathrm{~cm}$ layers was reduced by $9.7 \%$ with precipitation $<400 \mathrm{~mm}$, followed by $21.9 \%$ and $10.6 \%$ increase with precipitation $400-800 \mathrm{~mm}$ and $>800 \mathrm{~mm}$. The results indicated that the accumulation of SOC content after restoration from cropland in middle and high- precipitation regions were higher than that in low precipitation region in $0-20 \mathrm{~cm}$ and $20-40 \mathrm{~cm}$ soil layers. However, the accumulation of SOC content after restoration from cropland in middleprecipitation was higher than high and low precipitation regions in deeper layers. In addition, in low-precipitation region, the SOC content was decreased in soil layer $>20$ $\mathrm{cm}$, indicating the loss of SOC in deeper soil layers may occur by restoration from cropland in arid area.

After the restoration from non-cropland, SOC content at $0-20 \mathrm{~cm}$ soil was increased by $70.5 \%, 54.1 \%$ and $31.4 \%$ with precipitation $<400 \mathrm{~mm}, 400-800 \mathrm{~mm}$ and $>$ $800 \mathrm{~mm}$, respectively (Fig. 5b). While increase of $26.6 \%, 38.6 \%$ and $18.4 \%$ in SOC content at $20-40 \mathrm{~cm}$ soil were observed with precipitation $<400 \mathrm{~mm}, 400$ $800 \mathrm{~mm}$ and $>800 \mathrm{~mm}$. For the $40-60 \mathrm{~cm}$ soil, SOC content at which increased by $41 \%, 62.7 \%$ and $43.8 \%$ with precipitation $<400 \mathrm{~mm}, 400-800 \mathrm{~mm}$ and $>800 \mathrm{~mm}$, respectively. However, SOC content at $>60 \mathrm{~cm}$ soil increased by $42.9 \%, 46.5 \%$ and $17.6 \%$ with precipitation $<$ $400 \mathrm{~mm}, 400-800 \mathrm{~mm}$ and $>800 \mathrm{~mm}$, respectively.
These results suggested that the response ratios of the SOC content in the restoration from non-cropland were higher than that in the restoration from cropland, with no conspicuous land-use change, the SOC content were increased in three group regions in all soil layers, and the accumulation rates of SOC content decreased with MAP increasing in surface $0-20 \mathrm{~cm}$ layer. In addition, the accumulation rates of SOC content in middleprecipitation was higher than high and low precipitation regions.

\subsection{Effects of mean annual temperature on SOC}

The effects of MAT on SOC at different soil depth were shown in Fig. 6. SOC contents tended to increase as MAT elevated. After cropland conversion, SOC content at surface soil $(0-20 \mathrm{~cm})$ increased by $38.7 \%, 41.5 \%$ and $44.2 \%$ with MAT $<6^{\circ} \mathrm{C}, 6^{\circ} \mathrm{C}-10^{\circ} \mathrm{C}$ and $>10^{\circ} \mathrm{C}$, respectively (Fig. 6a). In the deeper soil $(20-40 \mathrm{~cm})$, SOC content increased by $11.5 \%, 16.5 \%$ and $31.9 \%$ with MAT $<6^{\circ} \mathrm{C}, 6^{\circ} \mathrm{C}-10^{\circ} \mathrm{C}$ and $>10^{\circ} \mathrm{C}$, respectively. In soil depth of 40-60 cm, SOC content showed highest increase by $14.7 \%$ with MAT $6^{\circ} \mathrm{C}-10^{\circ} \mathrm{C}$, followed by $5 \%$ increase with MAT $>10^{\circ} \mathrm{C}$, while reduced by $11.7 \%$ with MAT $<6^{\circ} \mathrm{C}$. SOC content at $>60 \mathrm{~cm}$ soil increased by $21.2 \%$ and $9.3 \%$ with MAT $6^{\circ} \mathrm{C}-10^{\circ} \mathrm{C}$ and $>10^{\circ} \mathrm{C}$, but decreased by $2.8 \%$ with MAT $<6{ }^{\circ} \mathrm{C}$ (Fig. 6a). These results indicated that the response ratios of the SOC content in the restoration from cropland was not significantly different among the three groups in surface 

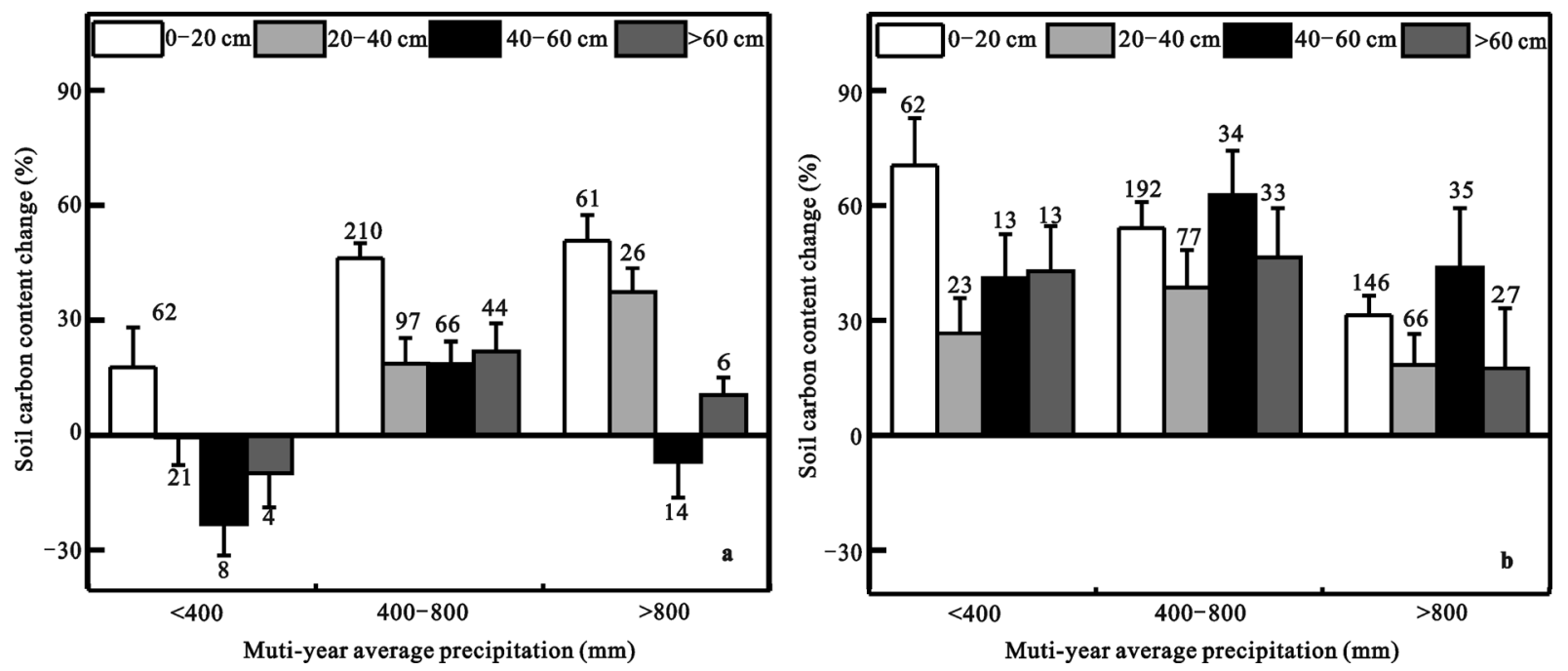

Fig. 5 Response ratios pertaining to the effects of MAP on soil organic carbon contents at different soil depths. (a) Restoration form cropland, (b) Restoration form non-cropland. The error bars represent 95\% confidence intervals (CI) and values above the bars are the corresponding number of observations

0-20 cm, and increased in $20-40 \mathrm{~cm}$ layers with the MAT increased. In addition, in deeper soil layers, the SOC content was decreased in cold regions and the accumulation rates of SOC in middle-temperature was higher than that in warmer and colder regions.

Following non-cropland conversion, SOC content at $0-20 \mathrm{~cm}$ soil increased by $43.1 \%, 78.2 \%$ and $24.5 \%$ with MAT $<6^{\circ} \mathrm{C}, 6^{\circ} \mathrm{C}-10^{\circ} \mathrm{C}$ and $>10^{\circ} \mathrm{C}$, respectively (Fig. 6b). At $20-40 \mathrm{~cm}$ soil, highest increase of SOC (63.9\%) was observed with MAT $<6^{\circ} \mathrm{C}$, followed by $27.9 \%$ and $11.8 \%$ increase with MAT $6^{\circ} \mathrm{C}-10^{\circ} \mathrm{C}$ and $>$ $10^{\circ} \mathrm{C}$. SOC content at $40-60 \mathrm{~cm}$ soil gained highest in-

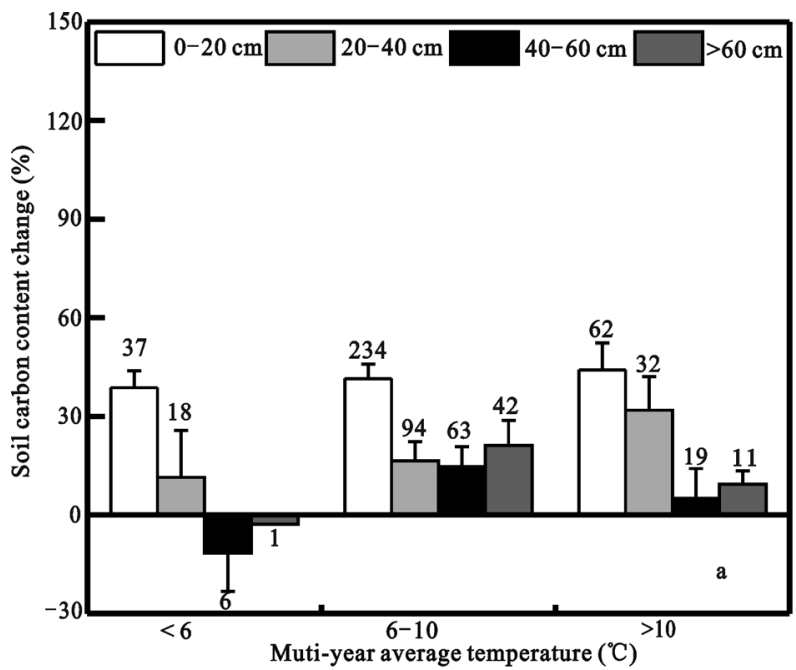

crease $(116 \%)$ with MAT $<6^{\circ} \mathrm{C}$, followed by $41 \%$ and $34.2 \%$ increase with MAT $>10^{\circ} \mathrm{C}$ and $6^{\circ} \mathrm{C}-10^{\circ} \mathrm{C}$. In addition, SOC content at $>60 \mathrm{~cm}$ soil increased by $75 \%$, $46.2 \%$ and $8.1 \%$ with MAT $<6^{\circ} \mathrm{C}, 6^{\circ} \mathrm{C}-10^{\circ} \mathrm{C}$ and $>10^{\circ} \mathrm{C}$ following the restoration from non-cropland. These results suggested that the response ratios of the SOC content in the restoration from non-cropland were significantly higher than that in the restoration from cropland. Partly due to no conspicuous land-use change, the SOC contents were increased in three group regions in all soil layers, and the accumulation rates of SOC decreased with the MAT increased except in surface $0-20 \mathrm{~cm}$ layer.

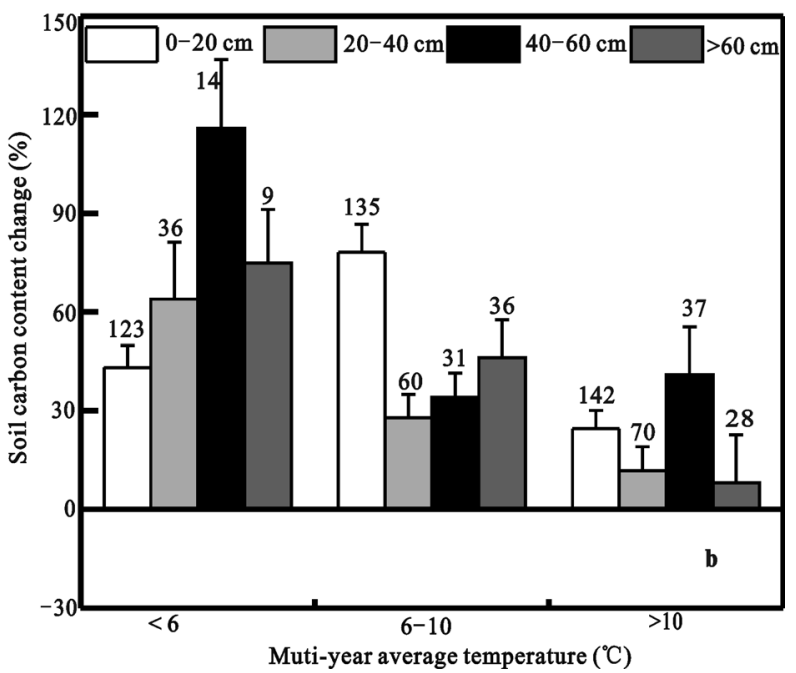

Fig. 6 Response ratios pertaining to the effects of MAT on soil organic carbon contents at different soil depths. (a) Restoration from cropland, (b) Restoration from non-cropland. The error bars represent 95\% confidence intervals (CI) and values above the bars are the corresponding number of observations 
3.6 Factors affecting SOC under vegetation restoration

The statistical analysis of the between-group heterogeneity $\left(Q_{b}\right)$ showed that the vegetation restoration had significant effects on the SOC at depths of $40-60 \mathrm{~cm}(P$ $<0.01$, Table 1). After the restoration from cropland, both the plantation type $(P<0.05)$ and conversion period $(P<0.001)$ had significant effects on the SOC in the $0-20 \mathrm{~cm}, 20-40 \mathrm{~cm}$ and $40-60 \mathrm{~cm}$ of soil, whereas these effects were not significant at a depth of $>60 \mathrm{~cm}$. After restoration from non-cropland, both the plantation type and conversion period $(P<0.001)$ had significant effects on the SOC in the $0-20 \mathrm{~cm}$ layer, whereas these effects were not significant at a depth of $40-60 \mathrm{~cm}$. Conversion period $(P<0.001)$ had significant effects on the SOC at a depth of $20-40 \mathrm{~cm}$, while the plantation type $(P<0.001)$ had no significant effects on the SOC at the depth of $>60 \mathrm{~cm}$.

Pearson correlation analysis showed that the response ratios of the SOC to vegetation restoration had correlation with mean annual precipitation (MAP) at the depth of top 0-20 cm (Table 2). Significant negative relationships were observed between the response ratios of the
SOC and MAT in soil layers $>20 \mathrm{~cm}$ after restoration from non-cropland, while positive correlation was observed between the response ratios of the SOC and MAP both in $0-20 \mathrm{~cm}$ and $20-40 \mathrm{~cm}$ soil layers. In addition, significantly negative relationships were also showed between the responses ratios of the SOC and the initial SOC content in cropland (control plot). in the $0-20 \mathrm{~cm}$, $20-40 \mathrm{~cm}$ and $>60 \mathrm{~cm}$ layers.

\section{Discussion}

The SOC content was determined by the carbon input from plant litter and the carbon output due to soil respiration (Vesterdal et al., 2002). Vegetation restoration has the potential to result in $\mathrm{C}$ accretion through the buildup of plant biomass and soil C (Zinn et al., 2005), and a large number of results were proved that the vegetation restoration may increase the SOC content in several ways: increasing the soil carbon input by affecting the net primary productivity (NPP) (Smith, 2008); reducing the loss of soil carbon while preventing soil erosion (Don et al., 2011); Decreasing soil carbon output by altering soil biological and chemical processes

Table 1 Effects of vegetation on between-group heterogeneity $\left(Q_{b}\right)$ in relation to soil organic carbon response ratio

\begin{tabular}{|c|c|c|c|c|}
\hline Depth (cm) & Conversion type & Categorical variable & $Q_{b}$ & $\mathrm{~F}$ \\
\hline \multirow[t]{5}{*}{$0-20$} & Total & Cropland/non-cropland & 0.80 & 1.40 \\
\hline & Restoration from cropland & Plantation type & $12.23^{* * *}$ & 16.63 \\
\hline & & Conversion period & $27.34^{* * *}$ & 21.10 \\
\hline & Restoration from non-cropland & Conversion approach & $10.02^{* * *}$ & 7.26 \\
\hline & & Conversion period & $7.89^{* * *}$ & 5.67 \\
\hline \multirow[t]{5}{*}{$20-40$} & Total & Cropland/non-cropland & 0.72 & 1.59 \\
\hline & Restoration from cropland & Plantation type & $2.26^{* *}$ & 3.49 \\
\hline & & Conversion period & $9.74^{* * *}$ & 8.86 \\
\hline & Restoration from non-cropland & Conversion approach & 1.45 & 1.33 \\
\hline & & Conversion period & $14.90^{* * *}$ & 6.32 \\
\hline \multirow[t]{5}{*}{$40-60$} & Total & Cropland/non-cropland & $6.94^{* * *}$ & 17.33 \\
\hline & Restoration from cropland & Plantation type & $1.40^{* *}$ & 3.53 \\
\hline & & Conversion period & $6.60^{* * *}$ & 11.74 \\
\hline & Restoration from non-cropland & Conversion approach & $6.07^{* * *}$ & 5.58 \\
\hline & & Conversion period & 2.88 & 0.95 \\
\hline \multirow[t]{5}{*}{$>60$} & Total & Cropland/non-cropland & 0.84 & 2.08 \\
\hline & Restoration from cropland & Plantation type & 0.97 & 2.61 \\
\hline & & Conversion period & 0.42 & 0.51 \\
\hline & Restoration from non-cropland & Conversion approach & $7.52^{* * *}$ & 8.16 \\
\hline & & Conversion period & 1.75 & 0.62 \\
\hline
\end{tabular}

Notes: *: $P<0.05 ; * *: P<0.01 ; * * *: P<0.001$ 
Table 2 Pearson correlation coefficients between soil organic carbon response ratio and other factors

\begin{tabular}{|c|c|c|c|c|c|}
\hline & Soil layer $(\mathrm{cm})$ & MAT & MAP & $S O C_{\mathrm{in}}$ & $N$ \\
\hline \multirow[t]{4}{*}{ Total } & $0-20$ & 0.010 & $0.120^{* *}$ & $-0.129^{* *}$ & 733 \\
\hline & $20-40$ & -0.105 & 0.023 & $-0.197^{* *}$ & 310 \\
\hline & $40-60$ & -0.109 & -0.024 & -0.006 & 170 \\
\hline & $>60$ & -0.167 & -0.117 & $-0.356^{* *}$ & 127 \\
\hline \multirow[t]{4}{*}{ Restoration from cropland } & $0-20$ & 0.044 & $0.157^{* *}$ & $-0.216^{* *}$ & 333 \\
\hline & $20-40$ & $0.173^{*}$ & $0.200^{*}$ & $-0.306^{* *}$ & 144 \\
\hline & $40-60$ & 0.035 & -0.056 & -0.116 & 88 \\
\hline & $>60$ & 0.008 & -0.038 & $-0.180^{* *}$ & 54 \\
\hline \multirow[t]{4}{*}{ Restoration from non-cropland } & $0-20$ & -0.003 & 0.094 & $-0.105^{*}$ & 400 \\
\hline & $20-40$ & $-0.260^{* *}$ & -0.102 & $-0.144^{*}$ & 166 \\
\hline & $40-60$ & $-0.263^{*}$ & -0.098 & -0.054 & 82 \\
\hline & $>60$ & $-0.259^{*}$ & -0.184 & $-0.406^{* *}$ & 73 \\
\hline
\end{tabular}

Notes: MAT: mean annual temperature; MAP: mean annual precipitation; $N$ : number of samples. *: $P<0.05$; **: $P<0.01 ; S O C_{\text {in }}$ : the initial $S O C$ content

(Post and Kwon, 2000; Laganière et al., 2010). In China, Song et al. (2014) reported that SOC contents in $0-20 \mathrm{~cm}$ layer significantly increased by $55.6 \%$ and $36.9 \%$ after the conversion of cropland to forest and grassland. In this work, abovementioned results suggested that the SOC content could be increased by vegetation restoration in china. The SOC content increased by $41.7 \%$ after vegetation restoration from cropland at soil depth of $0-20 \mathrm{~cm}$ (Fig. 2) was slightly lower than Song's report that SOC increased by $48.1 \%$ (Song et al., 2014). Moreover, the SOC accumulation rates (Fig. 2) under vegetation restoration from non-cropland were higher than that under vegetation restoration from cropland, indicating that SOC contents gained more incensement under non-cropland restoration than that under cropland restoration, especially in deeper soil layers $(>20 \mathrm{~cm})$. This phenomenon was probably due to longer conversion period of non-cropland than that of cropland in China. In addition, partly due to the cropland with slope gradient over $25^{\circ}$ and degraded/decertified barren land will be restored in China (Chang et al., 2011), soil carbon could be decreased during the early stage by soil erosion, resulting in a certain period of time for restoring the original level need (Turner et al., 2006 ).

\subsection{Conversion type}

The restoration type could also greatly affect the SOC accumulation by affecting carbon inputs and loss. It was widely accepted that SOC increased after the conversion of cropland to natural vegetation (Guo and Gifford, 2002; Don et al., 2011; Song et al., 2014). Guo and
Gifford (2002) reported that SOC stocks significantly increased by $18 \%, 53 \%$ and $19 \%$ after the conversion of cropland to plantation, secondary forest and pasture, respectively. Don et al. (2011) also proved that SOC stocks increased by $29 \%$ and $26 \%$ after conversion of cropland to forest and grassland. This study showed a similar rate of increase (Fig. 3a) to the rate reported by Guo and Gifford (2002). The result implied that the conversion of cropland to forest or shrub land was a more efficient way to accumulate carbon in soil than the conversion of cropland to grassland did. Moreover, the SOC was higher in shrub land than that in forest, which could be speculated that this trend occurred because $90 \%$ of the shrubs used in cropland restoration are $\mathrm{N}$-fixing. Such shrubs allocated more of their photosynthetic production into the deep soil layer compared to trees (Song et al., 2013). According to the previous studies, confusing results of soil $\mathrm{C}$ change were reported following the conversion of non-cropland to another vegetation type. For example, Guo and Gifford (2002) reported that SOC stocks increased by $8 \%$ after conversion of forest to pasture. Don et al. (2011) indicated that SOC stocks declined by $6.3 \%$ after conversion of forest to grassland. However, SOC stocks declined after the conversion of cropland or pasture to grassland at the early conversion period (Hopkins et al., 2009). When no conspicuous vegetation type change occurred after vegetation restoration, like pasture closure, forest tending and natural forest protection, the SOC increased by loss of carbon (Zhang et al., 2015), decreasing mechanical disturbance (Oudenhoven et al., 2015) and increasing aboveground biomass input(Cook et al., 2014). 
The response ratios of the SOC content in conversion of pasture to grassland was higher than conversion of plantation to forest at soil depths of 0-20 cm, 20-40 cm, while the SOC content conversion of pasture to grassland was less than conversion of plantation to forest at soil depths of 40-60 $\mathrm{cm}$ and $>60 \mathrm{~cm}$ (Fig. 3b). The reason might be that the growth of SOC need longer recovery time in deep soil layer, and the period of conversion of pasture to grassland was less than that of conversion of plantation to forest ( $\mathrm{Ni}$ et al., 2012). In this study, these result implied that forest protection could be conducive to the accumulation of SOC in deep soil.

\subsection{Conversion period}

With increasing period of vegetation restoration, there was an increase in carbon inputs due to the accumulation of the aboveground and below-ground biomass, accompanied by decrease of the soil temperature, enhancing water holding capacity and promoting SOC accumulation (Laganière et al., 2010; Shi et al., 2013). It was reported that conversion period was the important factors which affected SOC content after restoration. Because of the different local environmental conditions, land use history and restoration and management strategies (Shi et al., 2013), the amount of the SOC loss and the beginning time of net SOC accumulation were variable. The different results could be summarized as the following: 1) an increase (Mao et al., 2010; Deng et al., 2013); 2) a decrease (Muf et al., 2008; Smal and Olszewska, 2008); and 3) an initial decrease in soil C during the early stage, followed by a gradual return of $\mathrm{C}$ stocks to cropland levels and then continue to grow (Zhang et al., 2010; Karhu et al., 2011). In this study, SOC content decreased at the early stage of the restoration from the cropland to natural vegetation (1-5 yr), and return of SOC content to previous land use level may take 10 years or more in deep soil (Fig. 4a). This result could be explained by soil erosion on steep (most of the cropland were restored with slope gradient over $25^{\circ}$ ) slopes (Chang et al., 2011), by lack of litter input at the early stage because of the lower NPP (Knorr et al., 2005), and by increasing soil respiration rate via reducing vegetation (Curtis and Wang, 1998) and increasing dead roots pool. The result also showed that there were significant increases in the SOC content after $30 \mathrm{yr}$ restoration later as compared with that during $10-30 \mathrm{yr}$, especially in deeper layers, and indicated that vegetation types might change again after $30 \mathrm{yr}$. The increased rate of the SOC content in deeper layers was less than that of the surface layers and need a long restoration period back to the original level. However, under the restoration from non-cropland, due to the soil erosion reduced by unobvious land use and less disturbance after restoration, SOC content did not decrease at the early stage (except 40-60 cm), and the increased rate of the SOC content in deeper layers was faster for the surface layers in 6-20 yr, it could be explained by the SOC content with high level in surface layer and large dead roots pool in deeper layers in previous land. However, the significant increases of SOC content was delayed until $40 \mathrm{yr}$ later, and the SOC content after restoration $40 \mathrm{yr}$ was still lower than that in the natural forest $(>40 \mathrm{~cm})$, implying that the soil still have large carbon sequestration potential after vegetation restoration in China in the future.

\subsection{Climate factors}

Climate could affect soil $\mathrm{C}$ accumulation through temperature and precipitation, and influence both the productivity of vegetation and decomposition of litter by different soil and vegetation types (Li et al., 2012; Deng et al., 2014). At the global scale, the soil $\mathrm{C}$ accumulation after afforestation was found to vary with precipitation (Guo and Gifford, 2002; Shi et al., 2013). In China, annual average temperature and precipitation were not key factors affecting soil $\mathrm{C}$ stock change (Chang et al., 2011; Yang et al., 2011), and might affect some stages after land use change (Deng et al., 2014). In this study, it was found that the relative SOC change in the top soil $(0-20 \mathrm{~cm})$ after restoration was sensitive to MAP, while the relative SOC change in the top soil $(0-20 \mathrm{~cm})$ after restoration was sensitive to MAT after restoration from cropland. In addition, the relative SOC changes correlated with MAT significantly. However, annual average temperature and precipitation were not key factors affecting soil $\mathrm{C}$ stock change after both the restoration from cropland and non-cropland, such as the initial SOC or plantation type, these results could be supported by the study of Laganière et al. (2010). The reasons might be as follows: i) For the restoration from cropland, most sites involved in the current study were located in the arid and semiarid regions, especially the Loess Plateau of China, and the soil moisture significantly affected the 
accumulation of SOC (Chang, 2011), ii) the litter layer on the former grassland or forest might weaken the effects of climate factors on the SOC. In this study, the accumulation of SOC content after the restoration from cropland in middle-precipitation and high-precipitation regions were higher than that in low-precipitation region in $0-20 \mathrm{~cm}$ and $20-40 \mathrm{~cm}$ soil layers. In addition, the influence of MAT on the accumulation of SOC content was similar to MAP. In the low-precipitation and high-precipitation condition, SOC content was decreased in the deeper $(>40 \mathrm{~cm})$ layers. The reason might be that in the arid and semi-arid regions, slow accumulation of SOC was resulted from the slow input of the underground biomass at the early period (Beniston et al., 2014). Higher level precipitation increased NPP (Qiu et al., 2012), however, soil erosion might slow down the accumulation of soil organic carbon (Ma et al., 2016).

The response ratios of the SOC content after the restoration from non-cropland were increased in three group regions in all soil layers, which showed that the SOC content might decrease in the arid and cold regions after the restoration from cropland. Reasonable vegetation restoration types and managements might be need in arid and semi-arid regions.

\subsection{Uncertainty analyses}

In this study, the accumulation of SOC under the conversion to forest was higher than other restoration types in deeper layers $(>40 \mathrm{~cm})$, indicating an effective direction of carbon sequestration for terrestrial ecosystems as well as climate change mitigation in the future. However, the data available was limited especially in deeper soil layers $(>60 \mathrm{~cm})$ by the slow process in soil $\mathrm{C}$ accumulation, which might weaken the certainty of the results to some extent. In addition, 733 sites reviewed in this study, including 29 provinces, municipalities, and autonomous regions, which were mainly distributed in the eastern and middle parts (especially in the Loess Plateau) of China (Persson et al., 2013). Therefore, the results might affect by some dominant data from certain region. Moreover, the effect of tree species (Song et al., 2014), soil types (Chai et al., 2015) and topographical variations (Schulp and Verburg, 2009) on soil C change were not analyzed in this study, which might weaken the determination of the factors about soil organic carbon accumulation. During the Grain for Green Project, di- versities of soil erosion in different regions led to the significantly different changes of SOC content at the early period of restoration (Olson et al., 2016). In addition, community dynamics during the process of vegetation restoration had a significant impact on the accumulation of soil organic carbon (Liu et al., 2016). These differences could lead to unpredictable results.

\section{Conclusions}

Vegetation restoration could accumulate SOC in China. The SOC increased by $45.33 \%, 24.43 \%$, and $30.29 \%$, $27.98 \%$ at soil depths of $0-20 \mathrm{~cm}, 20-40 \mathrm{~cm}, 40-60 \mathrm{~cm}$ and $>60 \mathrm{~cm}$, respectively. The response of carbon accumulation to vegetation restoration was greater in the surface soil layer than in the deeper soil layers. The restoration from non-cropland was more efficient regarding the accumulating SOC than the restoration from cropland, especially in $>40 \mathrm{~cm}$ layers, and conversion to forest leads to greater SOC accumulation than conversion to other land use did. The initial time since the vegetation restoration was positively correlated with the SOC accumulation, and was contrast with the restoration from cropland. SOC content did not decrease at the early stage (except 40-60 cm) after the restoration from non-cropland. In addition, carbon sequestration still increased after 40-year vegetation restoration in China. Moreover, this study showed that the SOC content might decrease after the restoration from cropland in the low-precipitation and the low-temperature region, while the SOC content showed highest increase in the midprecipitation and the mid-temperature region after the restoration from cropland. In addition, the SOC content significantly increased after the restoration from noncropland in the low-precipitation and the low-temperature region, while increased slowly in high-precipitation and high-temperature region.

In China, most research on vegetation restoration has focused exclusively on conversion of cropland to forest or grassland. This work focused on SOC accumulation and changing rule after different conversion approaches in China. These findings provided more appropriate types to the accumulation of SOC stocks after the vegetation restoration, implying that SOC accumulation in terrestrial ecosystems after vegetation restoration had great potential to mitigate the effects of climate change in the future. 


\section{References}

Bai Wenjuan, Jiao Juying, Ma Xianghua et al., 2005. Soil environmental effects of artificial woods in abandoned croplands in the Loess hilly gullied region. Journal of Arid Land Resources and Environment, 19(s1): 135-141. (in Chinese)

Bashkin M A, Binkley D, 1998. Changes in soil carbon following afforestation in Hawaii. Ecology, 79(3): 828-833. doi: 10.1890/0012-9658(1998)079

Benayas J M R, Newton A C, Diaz A et al., 2009. Enhancement of biodiversity and ecosystem services by ecological restoration: a meta-analysis. Science, 325(5944): 1121-1124. doi: 10.1126/science. 1172460

Beniston J W, Dupont S T, Glover J D et al., 2014. Soil organic carbon dynamics 75 years after land-use change in perennial grassland and annual wheat agricultural systems. Biogeochemistry, 120(1): 37-49. doi: 10.1007/s10533-014-9980-3

Chai Hua, Yu Guirui, He Nianpeng et al., 2015. Vertical Distribution of Soil Carbon, Nitrogen, and Phosphorus in Typical Chinese Terrestrial Ecosystems. Chinese Geographical Science, 25(5): 549-560. doi: 10.1007/s11769-015-0756-z

Chang R Y, Fu B J, Liu G H et al., 2011. Soil carbon sequestration potential for 'Grain for Green' Project in Loess Plateau, China. Environmental Management, 48(6): 1158- 1172. doi: 10.1007/s00267-011-9682-8

Conant R T, Paustian K, Elliott E T et al., 2001. Grassland management and conversion into grassland: Effects on soil carbon. Ecological Applications, 11(2): 343-355. doi: 10.1890/ 1051-0761(2001)

Cook R L, Dan B, Mendes J C T et al., 2014. Soil carbon stocks and forest biomass following conversion of pasture to broadleaf and conifer plantations in southeastern Brazil. Forest Ecology and Management, 324(5): 37-45. doi: 10.1016/j. foreco.2014.03.019

Cooper H, Hedges L V, 1994. The Handbook of Research Synthesis. New York: Russell Sage Foundation, 29-38.

Curtis P S, Wang X Z, 1998. A meta-analysis of elevated $\mathrm{CO}_{2}$ effects on woody plant mass, form, and physiology. Oecologia, 113(3): 299-313. doi: 10.1007/s004420050381

Deng L, Liu G B, Shangguan Z P, 2014. Land use conversion and changing soil carbon stocks in China's Grain-for-Green' Program: a synthesis. Global Change Biology, 20(11): 3544-3556. doi: 10.1111/gcb12508

Deng L, Wang K B, Chen M L et al., 2013. Soil organic carbon storage capacity positively related to forest succession on the Loess Plateau, China. Catena, 110(11): 1-7. doi: 10.1016/ j.catena.2013.06.016

Don A, Schumacher J, Freibauer A, 2011. Impact of tropical land-use change on soil organic carbon stocks-a meta-analysis. Global Change Biology, 17(4): 1658-1670. doi: 10.1111/ j.1365-2486.2010.02336.x

Foley J A, Ruth D, Asner G P et al., 2005. Global consequences of land use. Science, 309: 570-574. doi: 10.1126/science. 1111772.

Guo L B, Gifford R M, 2002. Soil carbon stocks and land use change: a meta-analysis. Global Change Biology, 8(4): 345-360. doi: 10.1046/j.1354-1013.2002.00486.x

Guo, L B, Wang M B, Gifford R M et al., 2007. The change of soil carbon stocks and fine root dynamics after land use change from a native pasture to a pine plantation. Plant and Soil, 299(1-2): 251-262. doi: 10.1007/s11104-007-9381-7

Hopkins D W, Waite I S, Mcnicol J W et al., 2009. Soil organic carbon contents in long-term experimental grassland plots in the UK (Palace Leas and Park Grass) have not changed consistently in recent decades. Global Change Biology, 15(7): 1739-1754. doi: 10.1111/j.1365-2486.2008.01809.x

Houghton R A, Hackler J L, 1999. Emissions of carbon from forestry and land-use change in tropical Asia. Global Change Biology, 5(4): 481-492. doi: 10.1046/j.1365-2486.1999.00244.x.

Johnson D W, Curtis P S, 2001. Effects of forest management on soil $\mathrm{C}$ and $\mathrm{N}$ storage: meta-analysis. Forest Ecology and Management, 140(2-3): 227-238. doi: 10.1016/ S0378-1127 (00)00282-6

Karhu K, Wall A, Vanhala P et al., 2011. Effects of afforestation and deforestation on boreal soil carbon stocks: comparison of measured C stocks with Yasso07 model results. Geoderma, 164(1): 33-45. doi: 10.1016/j.geoderma.2011.05.008

Knorr M, Frey S D, Curtis P S, 2005. Nitrogen additions and litter decomposition: a meta-analysis. Ecology, 86(12): 3252-3257. doi: 10.1890/05-0150

Laganière J, Angers D A, Pare' D et al., 2010. Carbon accumulation in agricultural soils after afforestation: a meta-analysis. Global Change Biology, 16(1): 439-453. doi: 10.1111/ j.13652486.2009.01930.x

Lal R, 2002. Soil carbon sequestration in China through agricultural intensification, and restoration of degraded and decertified ecosystems. Land Degradation and Development, 13(6): 469-478. doi: 10.1002/Ldr.531

Lal R, 2004. Soil carbon sequestration impacts on global climate change and food security. Science, 304(5677): 1623-1627. doi: 10.1126/science.1097396

Li D, Niu S, Luo Y, 2012. Global patterns of the dynamics of soil carbon and nitrogen stocks following afforestation: a meta analysis. New Phytologist, 195(1): 172-181. doi: 10.1111/ j.1469-8137.2012.04150.x

Li Yingnian, Guan Dingguo, Zhao Liang et al., 2005. Seasonal frozen soil and its effect on vegetation production in Haibei alpine meadow. Journal of Glaciology and Geoceyology, 27(3): 311-319. (in Chinese)

Liu H, Blagodatsky S, Giese M et al., 2016. Impact of herbicide application on soil erosion and induced carbon loss in a rubber plantation of Southwest China. Catena, 145: 180-192. doi: 10.1016/j.catena.2016.06.007

Ma W, Li Z, Ding K et al., 2016, Soil erosion, organic carbon and nitrogen dynamics in planted forests: a case study in a hilly catchment of Hunan Province, China. Soil and Tillage Research, 155: 69-77. doi: 10.1016/j.still.2015.07.007

Mao R, Zeng D H, Hu Y L et al., 2010. Soil organic carbon and nitrogen stocks in an age-sequence of poplar stands planted on marginal agricultural land in Northeast China. Plant and Soil, 
332(1): 277-287. doi: 10.1007/s11104-010-0292-7

Muf K, Guo L B, Gifford R M, 2008. Observed and modelled soil carbon and nitrogen changes after planting a Pinus radiata stand onto former pasture. Soil Biology and Biochemistry, 40(1): 247-257. doi: 10.1016/j.soilbio.2007.08.021

Ni K, Ding W, Cai Z et al., 2012. Soil carbon dioxide emission from intensively cultivated black soil in northeast china: nitrogen fertilization effect. Journal of Soils and Sediments, 12(7): 1007-1018. doi: 10.1007/s11368-012-0529-6

Nouvellon Y, Epron D, Marsden C et al., 2012. Age-related changes in litter input sex plain annual trends in soil $\mathrm{CO}_{2}$ effluxes over a full Eucalyptus rotation after afforestation of a tropical savannah. Biogeochemistry, 111(1): 515-533. doi: 10.1007/s10533-011-9685-9

Olson K R, Al-Kaisi M, Lal R et al., 2016. Impact of soil erosion on soil organic carbon stocks. Journal of Soil and Water Conservation, 71(3): 61A-67A. doi: 10.2489/jswc.71.3.61A

Oudenhoven A P E V, Veerkamp C J, Alkemade R et al., 2015. Effects of different management regimes on soil erosion and surface runoff in semi-arid to sub-humid rangelands. Journal of Arid Environments, 121: 100-111. doi: 10.1016/j.jaridenv. 2015.05.015

Paul K I, Polglase P J, Nyakuengama J G et al., 2002. Change in soil carbon following afforestation. Forest Ecology and Management, 168(1-3): 241-257. doi: 10.1016/S0378-1127(01) 00740-X

Persson M, Moberg J, Ostwald M et al., 2013. The Chinese grain for green programme: assessing the carbon sequestered vialand reform. Journal of Environmental Management, 126(14): 142-146. doi: 10.1016/j.jenvman.2013.02.045

Post W M, Kwon K C, 2000. Soil carbon sequestration and land-use change: processes and potential. Global Change Biology, 6(3): 317-327. doi: 10.1046/j.1365-2486.2000.00308.x

Qiu L, Wei X, Zhang X et al., 2012, Soil organic carbon losses due to land use change in a semiarid grassland. Plant and Soil, 355(1): 299-309. doi: 10.1007/s11104-011-1099-x

Richter D D, Markewitz D, Trumbore S E et al., 1999. Rapid accumulation and turnover of soil carbon in are-establishing forest. Nature, 400(6739): 56-58. doi: 10.1038/21867

Schulp C J E, Verburg P H, 2009. Effect of land use history and site factors on spatial variation of soil organic carbon across a physiographic region. Agriculture Ecosystems and Environment, 133(1-2): 86-97. doi: 10.1016/j.agee.2009.05.005

Shi S, Zhang W, Zhang P, et al., 2013. A synthesis of change in deep soil organic carbon stores with afforestation of agricultural soils. Forest Ecology \& Management, 296(3): 53-63. doi: 10.1016/j.foreco.2013.01.026

Smal H, Olszewska M, 2008. The effect of afforestation with Scots pine (Pinus silvestris L.) of sandy post-arable soils on their selected properties. II. Reaction, carbon, nitrogen and phosphorus. Plant and Soil, 305(1): 171-187. doi: 10.1007/s 11104-008-9538-z
Smith P, 2008. Land use change and soil organic carbon dynamics. Nutrient Cycling in Agroecosystems. 81(2): 169-178. doi: 10.1007/s10705-007-9138-y

Song X, Peng C, Jiang H et al., 2013. Direct and indirect effects of UV-B radiation on litter decomposition: a meta-analysis. Plos One, 8(6): e68858. doi: 10.1371/journal. pone. 0068858

Song X, Peng C, Zhou G et al., 2014. Chinese Grain for Green Program led to highly increased soil organic carbon levels: a meta-analysis. Scientific Reports, 4(3): 528-528. doi: 10. 1038/srep04460

State Forestry Administration, China, 2013. China Forestry Statistical Yearbook (2012). Beijing: China Forestry Press, 38-45.

Turner J, Lambert M J, Johnson D W, 2006. Experience with patterns of change in soil carbon resulting from forest plantation establishment in eastern Australia. Forest Ecology and Management, 220(1): 259-269. doi: 10.1016/j.foreco.2005. 08.025

Van K C, Venterea R, Six J et al., 2013.Climate, duration, and N placement determine $\mathrm{N}_{2} \mathrm{O}$ emissions in reduced tillage systems: a meta-analysis. Global Change Biology 19(1): 33-44. doi: 10.1111/j.1365-2486.2012.02779.x

Vesterdal L, Ritter E, Gundersen P, 2002. Change in soil organic carbon following afforestation of former arable land. Forest Ecology and Management, 169(1-2): 137-147. doi: 10.1016/ S0378-1127(02)00304-3

Wang R, Filley T R, Xu Z et al., 2014. Coupled response of soil carbon and nitrogen pools and enzyme activities to itrogen and water addition in a semi-arid grassland of Inner Mongolia. Plant and Soil, 381(1): 323-336. doi: 10.1007/s11104-0142129-2n

Xiao L, Liu G B, Xue S et al., 2013. Soil microbial community composition during natural recovery in the Loess Plateau, China. Journal of Integrative Agriculture, 12(10): 1872-1883. doi: 10.1016 /S2095-3119(13)60399-8

Yang Y H, Luo Y Q, Finzi A C, 2011. Carbon and nitrogen dynamics during forest stand development: a global synthesis. New Phyologist, 190(4): 977-989. doi: 10.1111/j.1469-8137. 2011.03645.x

Zhang J H, Wang Y, Li F C, 2015. Soil organic carbon and nitrogen losses due to soil erosion and cropping in a sloping terrace landscape. Soil Research, 53(1): 87-96. doi: 10.1016/j. catena.2016.06.007

Zhang K, Dang H, Tan S et al., 2010. Change in soil organic carbon following the 'Grain-for-Green' programme in China. Land Degradation and Development, 21(1): 13-23. doi: 10. 1002/Ldr.954

Zhou G Y, Liu S G, Li Z et al., 2006. Old-growth forests can accumulate carbon in soils. Science, 314(5804): 1417-1417. doi: 10.1126/science. 1130168

Zinn Y L, Lal R, Resck D V S et al., 2005. Changes in soil organic carbon stocks under agriculture in Brazil. Soil and Tillage Research, 84(1): 28-40. doi: 10.1016/j.still.2004.08.007 